\title{
Variability of ionospheric scintillation near the equatorial anomaly crest of the Indian zone
}

\author{
S. Chatterjee and S. K. Chakraborty \\ Department of Physics, Raja Peary Mohan College, Uttarpara, Hooghly, Pin-712258, India \\ Correspondence to: S. K. Chakraborty (skchak2003@yahoo.com) \\ Received: 23 September 2012 - Revised: 31 January 2013 - Accepted: 5 February 2013 - Published: 19 April 2013
}

\begin{abstract}
Multistation observations of ionosphere scintillation at VHF $(250 \mathrm{MHz})$ and GNSS L1 frequency from three locations - (i) Bokkhali (BOK) (geographic $21.6^{\circ} \mathrm{N}$, $88.2^{\circ}$ E, dip $31.48^{\circ}$ ), (ii) Raja Peary Mohan College Centre (RPMC) (geographic $22.66^{\circ} \mathrm{N}, 88.4^{\circ} \mathrm{E}$, dip $33.5^{\circ}$ ) and (iii) Krishnath College Centre (KNC), Berhampore (geographic $24.1^{\circ} \mathrm{N}, 88.3^{\circ} \mathrm{E}$, dip $35.9^{\circ}$ ) - at $\sim 1^{\circ}$ latitudinal separations near the northern crest of the equatorial ionization anomaly (EIA) of the Indian longitude sector are investigated in conjunction with total electron content (TEC) data and available ionosonde data near the magnetic equator to study fine structure in spatial and temporal variability patterns of scintillation occurrences. The observations are carried out in the autumnal equinoctial months of a high solar activity year (2011). In spite of smaller latitudinal/spatial separation among the observing stations, conspicuous differences are reflected in the onset time, duration, fade rate and fade depth of VHF scintillations as well as in spectral features. Scintillations are mostly associated with depletion in TEC around the anomaly crest and occurrence of ESF near the magnetic equator at an earlier time. Not only the strength of EIA, but also the locations of observing stations with respect to the post-sunset resurgence peak of EIA seem to play dominant role in dictating the severity of scintillation activity. A secondary enhancement in diurnal TEC in the post-sunset period seems to accentuate the irregularity activities near the anomaly crest, and a threshold value of the same may fruitfully be utilized for the prediction of scintillation around the locations. An idea regarding latitudinal extent of scintillation is developed by considering observations at L1 frequency from the GPS and GLONASS constellation of satellites. A critical value of $h^{\prime} F$ near the magnetic equator for the occurrence of simultaneous scintillation at the three centres is
\end{abstract}

suggested. The observations are discussed considering electrodynamical aspect of equatorial irregularities.

Keywords. Radio science (Ionospheric physics)

\section{Introduction}

With the increasing reliance of our society on space-based technology, study of ionospheric scintillation has become one of the important components of the current space research activities. Ionospheric scintillation refers to random fluctuations in amplitude and phase of radio signals traversing a region of turbulence in the ionosphere. The deep/sustained fades or high fade rates due to scintillation may cause data loss in satellite communication/navigation links, loss of signal lock for a GPS satellite and greater noise levels in surveillance radars, reducing target discrimination and phase coherent integration for imaging. Ionospheric scintillation not only affects satellite communication, but also satellite measurement of ionospheric parameters (Knepp, 2004). Indeed, any ionospheric effect on radio communication is dependent upon the degree of (i) system adaptivity and robustness (i.e. sensitivity to variations in median signal level) and (ii) range of ionospheric variability. A fixed system design (receiver structure) is based upon the specifications of a required system margin. As long as the margin is not exceeded the faithful operation is obtained. The approach requires an estimate of the level of impairment that must be accounted for, which in turn needs knowledge of the magnitude of important ionospheric effects along with its occurrence distribution. Different ionospheric effects are controlled by ionospheric variability. Ionospheric scintillation results from such variability that depends on various geophysical parameters among which location of the 
observing station plays a dominant role. The ionosphere near the anomaly crest exhibits extreme variability under various geophysical and geomagnetic conditions.

Though much study has been done (Bhar et al., 1970; Somayajulu et al., 1984; Dabas and Reddy, 1986, 1990; Kil et al., 2002; Valladares et al., 2001, 2004; Carrano et al., 2012) on the spatial variations of scintillation in the low latitude zone, space-time variability of the same within a short latitudinal span around the crest of the equatorial ionization anomaly is yet to be explored. The study may throw some light on the fine structures of the space-time variability of scintillation, and results obtained may fruitfully utilized to decide the system vulnerability and corresponding solutions for adaptivity.

The post-sunset scintillation near the anomaly crest is mainly produced by equatorial electron density irregularities. At the magnetic equator around sunset, the F-layer may rapidly rise and develop a steep bottomside density gradient due to the combined effects of recombination of the F1 and $\mathrm{E}$ layers and an actual increase in the vertical plasma velocity due to pre-reversal enhancement (PRE) of an eastward electric field. This results in an F-layer plasma density profile which is unstable to the Rayleigh-Taylor ( $\mathrm{R}-$ T) instability (Ossakow, 1981). Onset of this instability results in upwelling of low-density bottomside plasma, known as bubbles, which are often generated in bursts rather than at nearly uniform interval (Burke et al., 2003). The average plasma density within the bubbles is reduced by $1-4$ orders of magnitude relative to the background ionosphere (Basu et al., 2002). Once generated, the bubbles move upward and sometimes attain an altitude greater than $1000 \mathrm{~km}$ above the magnetic equator. As the field-aligned plasma bubbles rise in the equatorial ionosphere, the low latitude extremities of the bubble propagate away from the equator in such a way that upper height limit defines the latitudinal extent of the bubble (Abdu et al., 1983). Indeed, a bubble is elongated thousands of kilometers in latitude and also occupies several degrees in longitude (Kelley et al., 2003). The altitude rise is one of the pre-conditions for observing scintillation at the off-equatorial locations. The walls and interiors of these depleted regions are characterized by ionospheric density fluctuations or irregularities over a range of scale sizes from kilometers to centimeters (Woodman and LaHoz, 1976; Basu and Basu, 1981). Meridional down-drafting of scintillation producing irregularities is the manifestation of the plasma bubble growth and dynamics over the equator. Transionospheric signals passing through the irregularities experience fluctuations in signal amplitude and phase, commonly known as scintillations. The depth of scintillation, i.e. the amplitude of signal fluctuations is directly related to the level of fluctuations in plasma density or the integrated electron density deviation $\left(\int \Delta N d l\right)$ along the ray path. It is controlled by irregularity amplitude $(\Delta N / N)$, background electron density $(N)$ and its distribution in the ionosphere. Though the irregularity amplitude does not change much with solar activity
(Basu et al., 1988) or from equatorial to anomaly crest region (de Paula et al., 2003), the background ionization density at the anomaly crest undergoes variation by a factor of 10 from high to low solar activity periods (Anderson, 1987; Basu et al., 1988). As the highest levels of electron density on Earth persist around the crest of the anomaly, it leads to larger integrated density deviations and hence intense scintillation activities, both amplitude and phase (Whalen, 2009, and references therein).

Several observations pertaining to climatology and dynamics of irregularities near the equatorial low-latitude zone have been made (Bhar et al., 1970; Somayajulu et al., 1984; Dabas and Reddy, 1986, 1990; Chakraborty et al., 1999; Kil et al., 2002; Valladares et al., 2001, 2004; Carrano et al., 2012). Bhar et al. (1970), using transit satellites BEB and BEC, showed that the irregularities in the low- to midlatitude transition zone are embedded in $\mathrm{N}-\mathrm{S}$ elongated clouds with the width tapering off towards north. Field alignment is weaker in transition zone than at the equator. Based on VHF nighttime scintillations recorded simultaneously at a meridian of chain stations in the Indian zone, Somayajulu et al. (1984) and Dabas and Reddy $(1986,1990)$ have shown that the latitudinal extent of post-sunset scintillation producing irregularities during the equinoctial months of high sunspot years is controlled by the generation and growth of F-region irregularities over the magnetic equator. Valladares et al. (2001) used TEC values measured with 6 GPS receivers forming a latitudinal chain to show that, during the equinoxes, a crest-to-trough ratio equal to 2 or larger always lead to the onset of UHF scintillations. Using GPS L1 frequency, latitudinal variation of scintillation activity was reported by Kil et al. (2002) from Brazil. While strong scintillation was reported (Valladares et al., 2004) during most of the days at the EIA region, at the magnetic equator strong scintillation is rarely observed. The strength of turbulence is reported (Carrano et al., 2012) to be larger near the crest of EIA and at early post-sunset hours.

Most of the multistation observations pertain to larger latitudinal separation among the observing stations. Multistation observations with smaller latitudinal separation $\left(\sim 1^{\circ}\right)$ or corresponding spatial separation of $150-200 \mathrm{~km}$ only near the anomaly crest are still lacking. The region, particularly in the Indian longitude zone, is densely populated and most susceptible to scintillation activities. The scintillation observations around the locations are of urgent need to identify the fine structures of scintillation occurrence patterns that must be accounted for in order to maintain uninterrupted transionospheric communication and navigation links. With this view, multistation scintillation observations are carried out in a campaign mode during the equinoctial months of a just ended high solar flux year (2011) from three locations: (i) Bokkhali (BOK) (geographic $21.6^{\circ} \mathrm{N}, 88.2^{\circ} \mathrm{E}$, dip $31.48^{\circ}$ ), (ii) Raja Peary Mohan College Centre (RPMC) (geographic $22.66^{\circ} \mathrm{N}, 88.4^{\circ} \mathrm{E}$, dip $33.5^{\circ}$ ) and (iii) Krishnath College Centre (KNC), Berhampore (geographic $24.1^{\circ} \mathrm{N}$, 


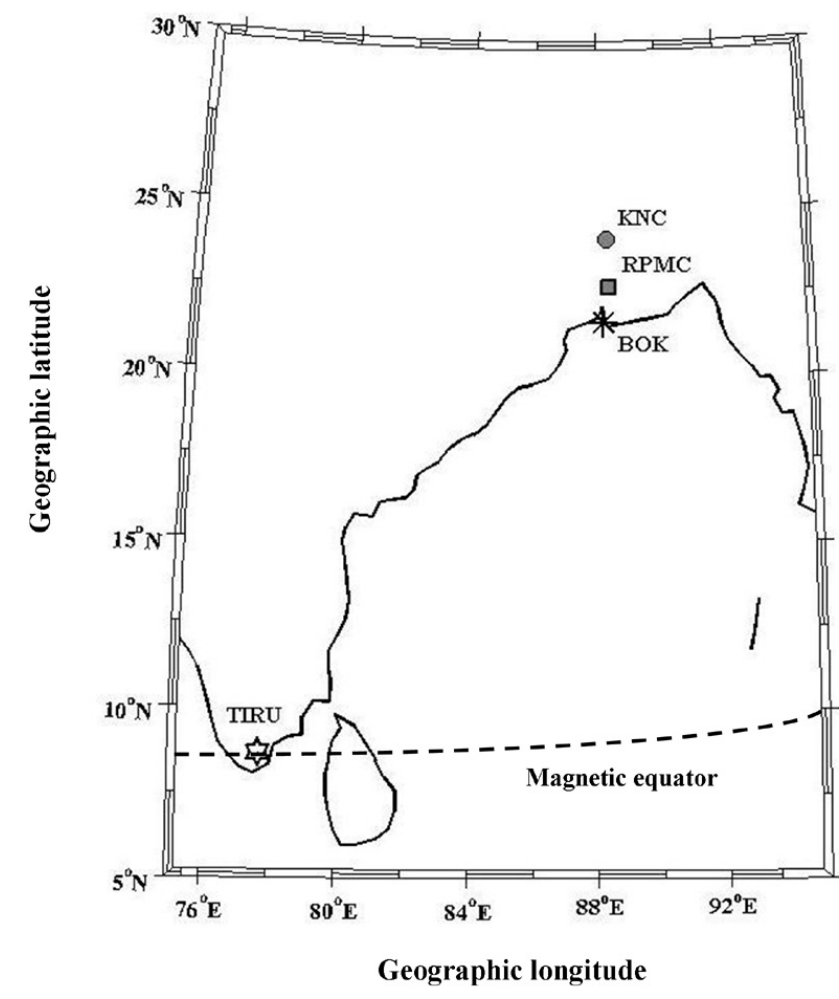

Fig. 1. Geographic locations of three observing stations: BOK $\left(21.6^{\circ} \mathrm{N}, 88.2^{\circ} \mathrm{E}\right), \mathrm{RPMC}\left(22.66^{\circ} \mathrm{N}, 88.4^{\circ} \mathrm{E}\right)$ and $\mathrm{KNC}\left(24.1^{\circ} \mathrm{N}\right.$, $\left.88.3^{\circ} \mathrm{E}\right)$ and the ionosonde centre at TIRUNELVELI (TIRU) $\left(8.73^{\circ} \mathrm{N}, 77.7^{\circ} \mathrm{E}\right)$. Dotted line indicates the average position of magnetic equator over the observation period.

$88.3^{\circ} \mathrm{E}$, dip $35.9^{\circ}$ ). The observing stations are located near the anomaly crest along the same meridian. The peculiar locations of the three stations, with respect to position of equatorial anomaly crest, reflects remarkable differences in the scintillation occurrence pattern which should be taken into account by the system engineers of transionospheric communications/navigation link design.

\section{Data}

Transionospheric signals at VHF $(250 \mathrm{MHz})$ from the geostationary satellite FSC are recorded simultaneously from three locations: (i) Bokkhali (geographic $21.6^{\circ} \mathrm{N}, 88.2^{\circ} \mathrm{E}$, geomagnetic $10.5^{\circ} \mathrm{N}, 161.7^{\circ} \mathrm{E}$, dip $31.48^{\circ}$ ), (ii) Raja Peary Mohan College Centre (RPMC) (geographic $22.66^{\circ} \mathrm{N}, 88.4^{\circ} \mathrm{E}$, geomagnetic $13.11^{\circ} \mathrm{N}, 161.9^{\circ} \mathrm{E}$, dip $33.5^{\circ} \mathrm{N}$ ) and (iii) $\mathrm{Kr}-$ ishnath College Centre (KNC), Berhampore (geographic $24.1^{\circ} \mathrm{N}, 88.3^{\circ} \mathrm{E}$, geomagnetic $14.6^{\circ} \mathrm{N}, 162^{\circ} \mathrm{E}$, dip $35.9^{\circ}$ ). The stations are situated at and around the EIA crest of Indian longitude sector (Fig. 1). The sub-ionospheric points (geographic) of the satellite paths are located at $\left(20.1^{\circ} \mathrm{N}\right.$, $\left.86.9^{\circ} \mathrm{E}\right),\left(21.1^{\circ} \mathrm{N}, 86.9^{\circ} \mathrm{E}\right)$ and $\left(22.4^{\circ} \mathrm{N}, 86.9^{\circ} \mathrm{E}\right)$ from Bokkhali, RPMC and $\mathrm{KNC}$, respectively. The receivers are calibrated at regular intervals of time, maintaining appropriate dynamic range, and the data are recorded at $50 \mathrm{~Hz} \mathrm{sam}-$ pling frequency. The intensity of scintillations is expressed by the $S_{4}$ index, defined as the normalized standard deviation of signal intensity fluctuations.

Fade rate, i.e. the rate of fading, may be measured by the (i) mean level crossing technique or by the (ii) Fourier technique which produces power spectra and time correlation functions (Whitney and Basu, 1977). For the present case, fade rate has been estimated by counting the number of peaks pertaining to the selected data section of the scintillation voltage patch following the mean level crossing technique in its initial phase (0-15 min), two middle phases (15-30 min and 30-45 $\mathrm{min}$ ) and decay phase (final $15 \mathrm{~min}$ ) for the post-sunset period and in three phases (initial: $0-15 \mathrm{~min}$, middle: 15 $30 \mathrm{~min}$ and final $15 \mathrm{~min}$ ) for the post-midnight period. Figure 2 is a sample amplitude scintillation (voltage) plot of 1min duration recorded at RPMC on 17 October 2011, which is used to calculate fade rate. The mean signal level and the estimated fade rate have also been shown in the figure.

For a reliable conversion of spatial irregularity spectrum into a temporal spectrum on the ground receiver power spectrum analysis has been carried out by selecting a stationary dataset, with the total number of data points used for performing the fast Fourier transform (FFT) being 1024. The analysis is performed under the assumption of "frozen in condition" (Yeh and Liu, 1982). For the present study it was carefully noted that the selected data portion corresponds to the more or less same $S_{4}$ value throughout the dataset. To satisfy the criteria for weak and moderate scintillations $S_{4}$ is chosen in the range $\approx 0.2-0.4$ and $\approx 0.4-0.8$, respectively (Basu et al., 1983). The power spectra are nothing but the Fourier transform of the autocorrelation function (Bhattacharya and Rastogi, 1985). In the present case, the auto correlation function is estimated by removing the linear trend from the input data segment. Thereby, a rectangular window is fitted to the auto correlation function and with the help of a low-pass filter FFT algorithm is applied to estimate the desired power spectrum. Spectral slopes are calculated by fitting a straight line to the high-frequency linear part of the semi-log power spectra versus frequency plot.

To compute the decorrelation time, the autocorrelation function corresponding to the chosen data section has been estimated. Then the time lag (in seconds) - corresponding to which the function has been dropped to $50 \%$ of its peak value - is noted. Similar to the fade rate measurement, four and three suitable sections of scintillation patches have been considered for post-sunset and post-midnight hours, respectively. For comparative study of spatial variability of various parameters like fade rates/fade depth and decorrelation time, only those scintillation patches having identical patterns of variation in voltage and $S_{4}$ pattern at the three locations are considered.

Using dual frequency GPS receivers, amplitude at L1 frequency and total electron content (TEC) along the signal path 


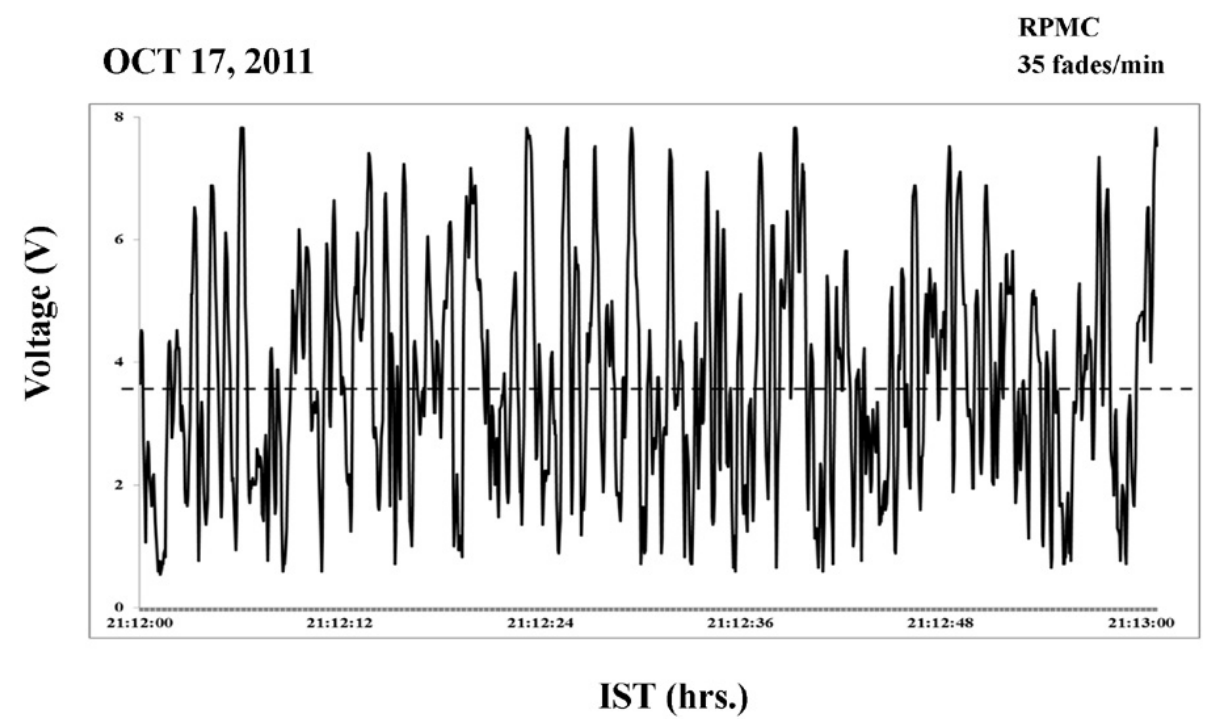

Fig. 2. Sample VHF (250 MHz) amplitude scintillation (voltage) record of 1-min duration observed at RPMC in the post-sunset period of 17 October 2011. The plot exemplifies the fade rate calculation. The dotted horizontal line indicates the mean signal level. Estimated fade rate (calculated following mean level crossing technique) is also shown.

are recorded simultaneously from two locations: RPMC and KNC. To avoid the multipath effect an elevation cut-off of $20^{\circ}$ is selected. For GPS TEC data an elevation cut-off of $50^{\circ}$ is considered to make the slant to vertical conversion more accurate (Paul et al., 2005). Appropriate satellite and receiver bias corrections are incorporated.

To have an idea of latitudinal variation of ionization, IGS TEC data at 15-min intervals are downloaded from the website http://cdaweb.gsfc.nasa.gov. The inherent deficiency of IGS data is $2.5^{\circ}$ latitudinal resolutions, which seem to be somewhat larger to reflect point-to-point correspondence, but the average picture may be assumed to be same.

To relate the observations from locations near the anomaly crest with that of the equatorial electrodynamics, ionosonde data from an equatorial station, Tirunelveli (geographic latitude $8.7^{\circ} \mathrm{N}, 77.8^{\circ} \mathrm{E}$, dip $3.15^{\circ}$ ) (Fig. 1), obtained from the Indian Institute of Geomagnetism in Mumbai, are also used.

The observations are made during the autumnal equinoctial months of just concluded high solar activity year (2011). The data for geomagnetically quiet $\left(d_{\mathrm{st}}>-50\right)$ and normal electrojet days are used for the present studies.

\section{Observations}

\subsection{General features of scintillation variability}

Multistation ionospheric scintillation observations for the period 1 September to 15 November 2011 of the autumnal equinoctial months of the high solar activity year have been analyzed under present investigations. During the period, F10.7 varies in the range from 121 to 190 solar flux units $\left(10^{-22} \mathrm{~W} \mathrm{~m}^{-2} \mathrm{~Hz}^{-1}\right)$. The period of investigation in- cludes 57 magnetically quiet days. In the post-sunset hours intense amplitude scintillations are recorded at VHF frequency with percentage occurrence of scintillation at about $55 \%$ and $50 \%$ of observing period at RPMC and KNC, respectively. For Bokkhali centre the database is available from 10 October 2011 onwards. It includes 18 and 4 days of VHF scintillations during post-sunset hours in the months of October and November 2011, respectively. Not only in the postsunset period, VHF scintillations are also found to initiate in the post-midnight hours. The numbers of such cases are 12,11 and 9 at BOK, RPMC and KNC, respectively, during the period of observation. Though the latitudinal separations among the three observing stations are not very large, remarkable differences are reflected in the occurrence pattern of VHF scintillations. The differences are observed in the onset time, amplitude ( $S_{4}$ pattern), fade rate and duration of scintillations. Figure 3 is a sample plot to demonstrate the difference in the scintillation activity at three locations as expressed by temporal variation of $S_{4}$ pattern pertaining to the (a) post-sunset and (b) post-midnight period. The datewise distribution of VHF scintillation at three locations is portrayed in Fig. 4. Scintillations (as reflected through the increase in the $S_{4}$ index over 0.2) initiate earlier at BOK, followed by RPMC and KNC in all cases. Generally, scintillations in the post-sunset period are recorded with a time lag of about 5-10 min between BOK and RPMC in the majority of cases, while the time delay between RPMC and KNC is found to be in excess of $10 \mathrm{~min}$. During post-midnight hours a similar temporal hierarchy in the onset time, i.e. earlier initiation at BOK followed by RPMC and KNC, is observed. Though onset time differences in the post-midnight period between BOK and RPMC in most of the cases varies in the 
17 Oct, 2011

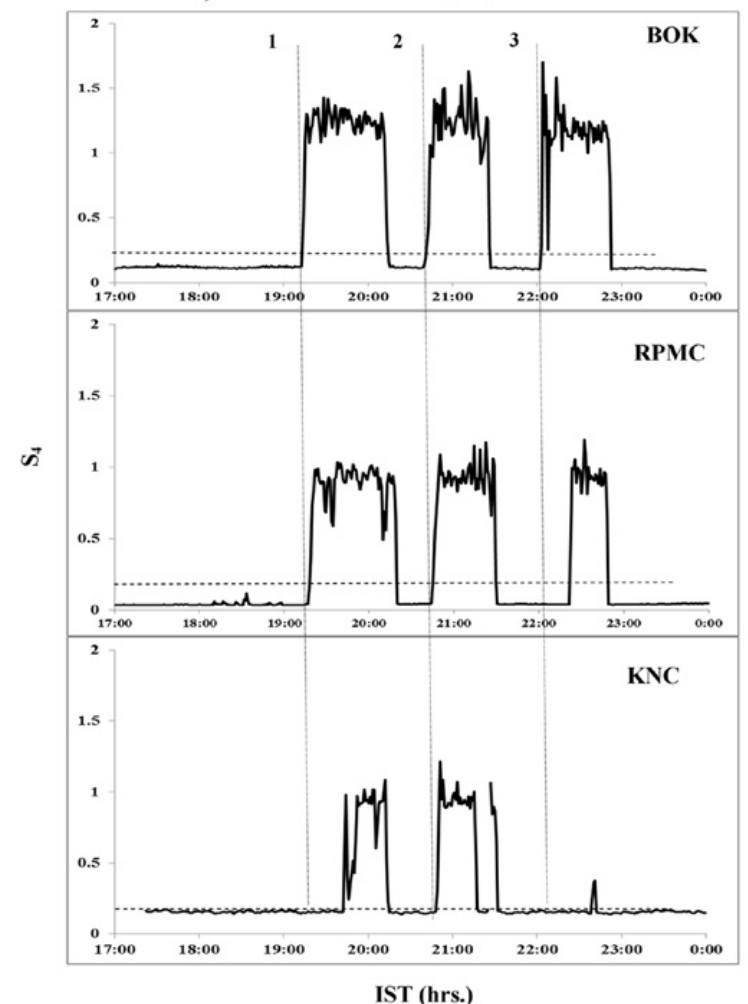

17 Oct, 2011 (b) Post-midnight

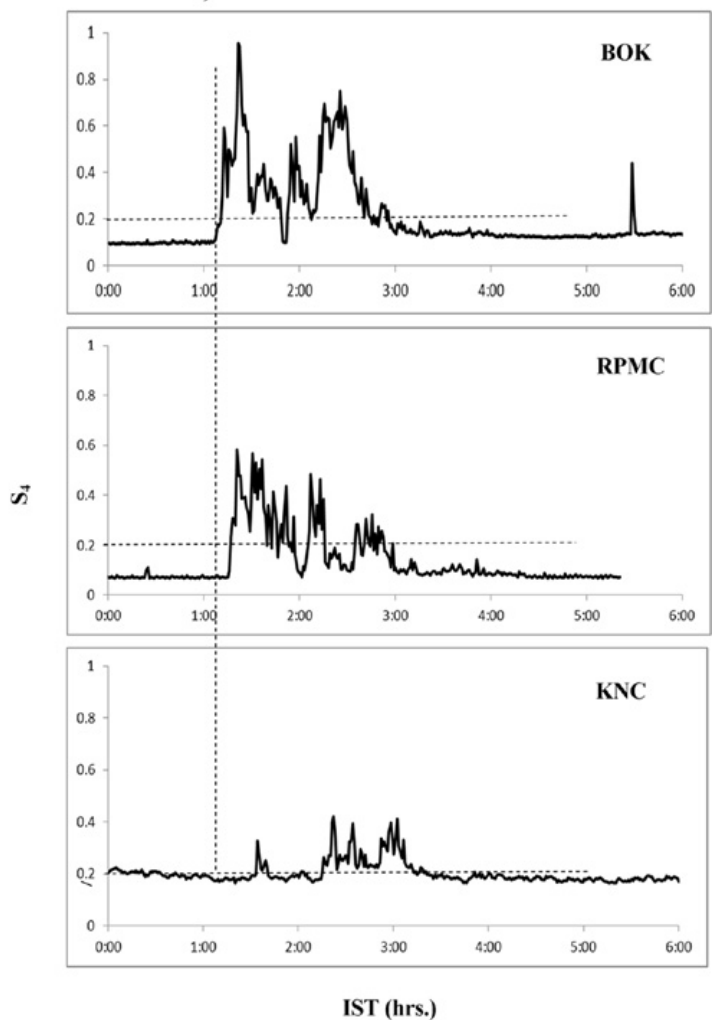

Fig. 3. Temporal variation of $S_{4}$ indices at VHF (250 MHz) as observed from BOK (uppermost panel), RPMC (middle panel) and KNC (lowest panel) during (a) post-sunset and (b) post-midnight period on 17 October 2011. The horizontal dotted line in the plot corresponds to $S_{4} \approx 0.2$.

range from 5 to $15 \mathrm{~min}$, scintillations with about 30-min time delay are also noted. At KNC the time lag of about $30-50 \mathrm{~min}$ behind RPMC is reflected. A comparatively greater value of the initiation time difference in the post-midnight hours compared to the post-sunset period may be attributed to the lesser vertical rise velocity of the irregularity cloud near the magnetic equator.

For the design of receiving systems, important considerations should be the fade margin and adaptive capability of the receiver to maintain the lock condition during the period of scintillation. A study of variability in scintillation interval along with fade depth is important for deciding the adaptive capability of the receiving system as loss of tracking and acquisition time are mostly dependent on these factors (Kinter et al., 2001). A distribution of an average scintillation patch duration at three locations is depicted in Fig. 5. Normally, short duration patches $(<15 \mathrm{~min})$ are populated at $\mathrm{KNC}$, while $\mathrm{BOK}$ is dominated by long-duration patches in the post-sunset hours. During the post-midnight period, a higher percentage occurrence irrespective of duration is reflected at BOK. The patchy characteristics of scintillation at $\mathrm{KNC}$ results from the width tapering nature and evolution of the filamentary structure of NS elongated irregularity clouds
(Bhar et al., 1970). VHF scintillation with peak-to-peak fluctuations $>30 \mathrm{~dB}$ at RPMC are recorded for $82 \%$ cases, while at $\mathrm{KNC}$ fluctuations in excess of $20 \mathrm{~dB}$, lower than the former, are noted for all scintillation cases. A much higher peakto-peak fluctuation, mostly exceeding $>35 \mathrm{~dB}$, at BOK is observed in $83 \%$ cases. A deep fade may exceed the fade margin of the receiving system leading to cycle slip and message error, and this together with longer duration may lengthen the acquisition time. In this perspective BOK seems to be most vulnerable. The hourly percentage occurrence for various ranges of $S_{4}$ values pertaining to intense $\left(S_{4}>0.8\right)$, moderate $\left(S_{4} \sim 0.4-0.8\right)$ and weak $\left(S_{4} \sim 0.2-0.4\right)$ scintillation are shown in Fig. 6, which demonstrates relative susceptibility of three locations in exhibiting various levels of scintillation. KNC records much lower percentage occurrence of strong scintillation, while intense scintillation plague both the post-sunset and post-midnight ionosphere over BOK. The post-midnight ionosphere over RPMC and $\mathrm{KNC}$ is mostly dominated by moderate to weak scintillation.

Distinguishing traits are also observed in the fade rates and respective decorrelation time (Table 1). A comparative study of average fade rate at three locations during the initial, middle and decay phase of scintillation patch is made 
Table 1. Average values of fade rate and decorrelation time for VHF scintillation in post-sunset and post-midnight period at three centres: BOK, RPMC and KNC. Total \# of scintillation days: 22 (BOK), 26 (RPMC), 25 (KNC) and 12 (BOK), 11 (RPMC), 9 (KNC) for post-sunset and post-midnight period.

\begin{tabular}{|c|c|c|c|c|c|c|c|c|}
\hline & \multirow{2}{*}{$\begin{array}{l}\text { Observation } \\
\text { centre }\end{array}$} & \multicolumn{4}{|c|}{ Post-sunset } & \multicolumn{3}{|c|}{ Post-midnight } \\
\hline & & $0-15 \min$ & $15-30 \mathrm{~min}$ & $30-45 \mathrm{~min}$ & final $15 \mathrm{~min}$ & $0-15 \mathrm{~min}$ & $15-30 \mathrm{~min}$ & final $15 \mathrm{~min}$ \\
\hline \multirow{3}{*}{$\begin{array}{l}\text { Average fade rate } \\
\text { (fades/min) }\end{array}$} & (a) $\mathrm{BOK}$ & $29 \pm 1.5$ & $36 \pm 2.6$ & $37 \pm 3.6$ & $18 \pm 3.3$ & $15 \pm 1.2$ & $18 \pm 1.5$ & $7 \pm 2.7$ \\
\hline & (b) RPMC & $25 \pm 3.7$ & $35 \pm 3.7$ & $34 \pm 3.1$ & $14 \pm 4.2$ & $7 \pm 0.8$ & $9 \pm 1.7$ & $5 \pm 0.7$ \\
\hline & (c) $\mathrm{KNC}$ & $15 \pm 4.6$ & $32 \pm 2.7$ & $25 \pm 1.8$ & $8 \pm 3.9$ & $5 \pm 0.2$ & $6 \pm 0.5$ & $3 \pm 0.35$ \\
\hline \multirow{3}{*}{$\begin{array}{l}\text { Average decorrelation } \\
\text { time }(\mathrm{s})\end{array}$} & (a) $\mathrm{BOK}$ & $0.63 \pm 0.04$ & $0.1 \pm 0.02$ & $0.08 \pm 0.01$ & $0.75 \pm 0.03$ & $1.65 \pm 0.4$ & $1.0 \pm 0.4$ & $1.7 \pm 0.35$ \\
\hline & (b) RPMC & $1.02 \pm 0.12$ & $0.13 \pm 0.02$ & $0.15 \pm 0.01$ & $1.05 \pm 0.06$ & $2 \pm 0.4$ & $1.44 \pm 0.55$ & $2.1 \pm 0.38$ \\
\hline & (c) $\mathrm{KNC}$ & $1.25 \pm 0.14$ & $0.18 \pm 0.03$ & $0.48 \pm 0.06$ & $1.45 \pm 0.29$ & $2.1 \pm 0.3$ & $1.55 \pm 0.2$ & $2.25 \pm 0.4$ \\
\hline
\end{tabular}

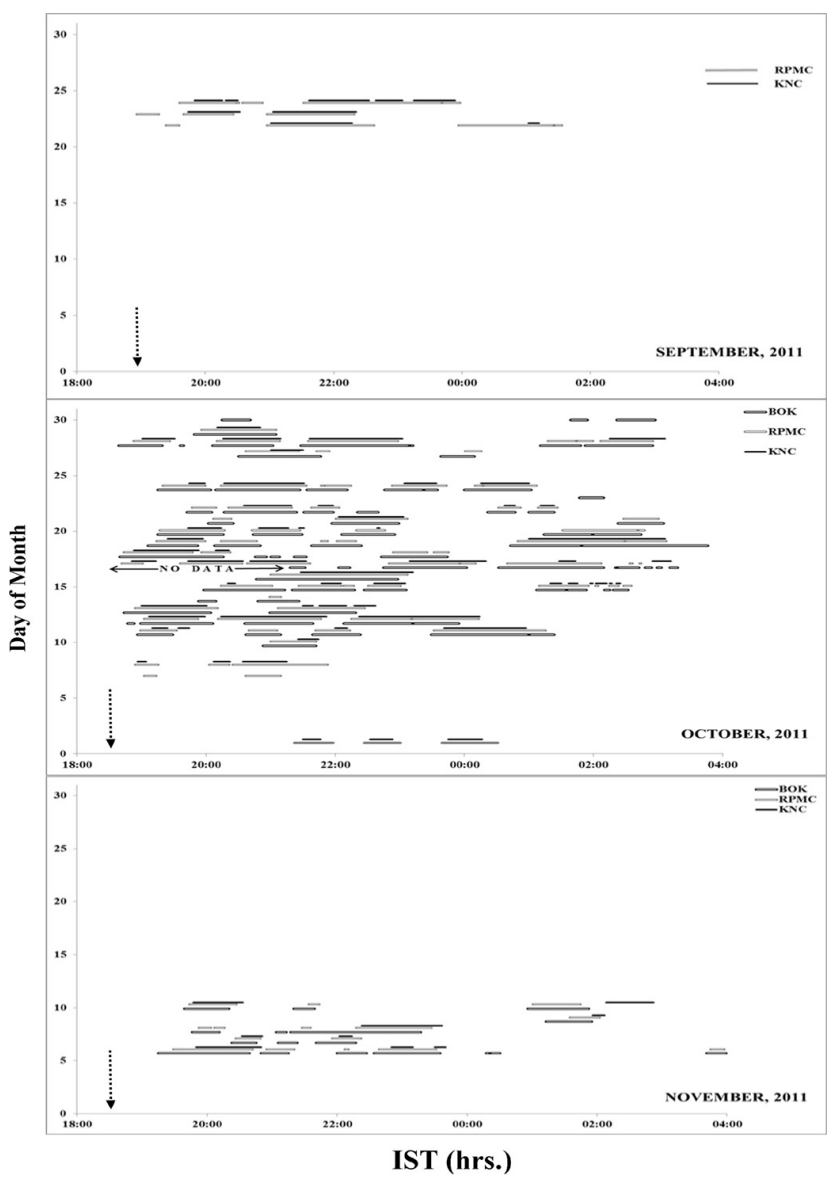

Fig. 4. Horizontal bar diagram showing date-wise distribution of scintillations $\left(S_{4}>0.2\right)$ at VHF frequency from three locations BOK, RPMC and KNC - during the observation period. The vertical arrows on time axis represent subionospheric (VHF) sunset time.

in Table 1. In all the three phases of scintillations, BOK recorded a higher rate of signal fluctuations compared to the others, and the same is more severe in the post-sunset period compared to the post-midnight ones. Though the fade rate recorded at $\mathrm{KNC}$ in the onset and decay phase is low, compa- rable fast signal fluctuations are evident in the middle of the patch. Within short spatial separation, prominent variations in the fade depth and fade rate are of major concern to the system engineers. The overall diminished fade rates during post-midnight hours indicate scintillations pertaining to irregularities of longer scale sizes compared to the post-sunset periods (Iyer et al., 2006). The fade rates depend on horizontal drift velocities of irregularities. A reduction in fade rates may be dictated by lower values of horizontal drift velocities and its larger spatial/temporal variability. The decorrelation time characterizes the rate of fluctuations of a signal (Carrano et al., 2012) that is estimated by the time at which the autocorrelation function of the signal falls to $50 \%$ of its peak value. It is a very good measure of the strength of scattering when the first-order statistics, as represented by the $S_{4}$ index, are completely saturated (Basu et al., 1983). Table 1 also gives an average picture of variation in decorrelation time at the initial, middle and decay phase of pre- and post-midnight VHF scintillations. KNC, being situated at the northern most location, exhibits the highest decorrelation time. In the developed phase of post-sunset scintillation, much lower values of decorrelation time, especially for BOK and RPMC, in the range $\approx 0.07-1.2 \mathrm{~s}$, are estimated, whereas at $\mathrm{KNC}$ the same is a little higher at $\approx 0.17-1.5 \mathrm{~s}$, indicating a decreased rate of peak-to-peak variation at $\mathrm{KNC}$ compared to $\mathrm{BOK}$ and RPMC. The lower values of decorrelation time correspond to fast fading in scintillation patches. It is reported that for severe scattering in the ionosphere, the decorrelation time reduces with the increase in the perturbation strength leading to saturated scintillation (Rino and Owen, 1980). For postmidnight hours all the three centres register higher values of decorrelation time, which lie in the range of $\approx 1.5-3.5 \mathrm{~s}$ at $\mathrm{KNC}$, while BOK and RPMC recorded comparatively lower decorrelation time than $\mathrm{KNC}$, ranging between 1.0-3.0, indicating diminished rate of peak-to-peak signal fluctuations. It is clear from above that all the fine structure parameters such as onset time, duration, fade depth, fade rates, decorrelation time etc. are notably different for the three centres in spite of the fact that the stations are located in a close vicinity to each other. 


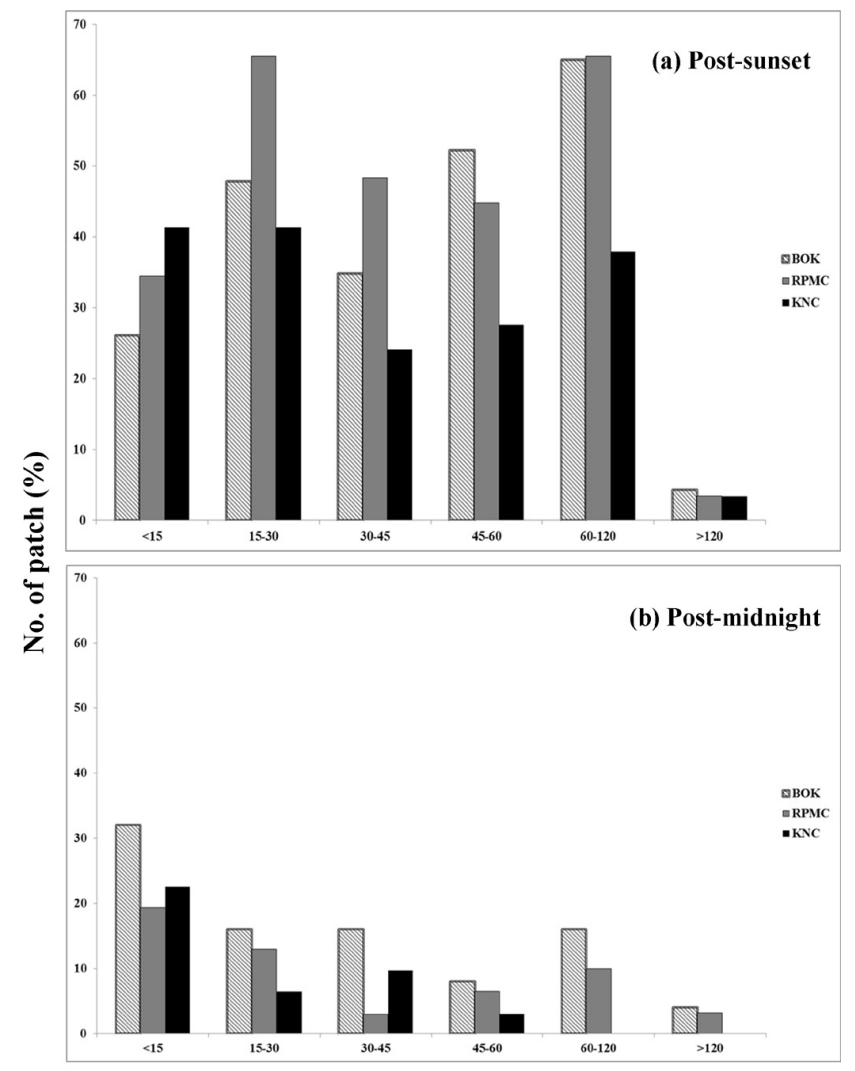

Scintillation patch time (minutes)

Fig. 5. Percentage occurrence of VHF scintillation patches with variable duration, as observed from three locations. Panels (a) and (b) pertain to post-sunset and post-midnight period respectively.

\subsection{Spectral features of scintillation variability}

Power spectral analysis of the VHF amplitude scintillation during post-sunset as well as post-midnight hours is carried out to have a look deep inside the fine structure variability pattern. The sample plots of power spectrum exhibiting the differences in the spectral slopes at three locations during the post-sunset and post-midnight period are given in Fig. 7a and b. Power spectra corresponding to post-sunset (post-midnight) scintillations are normally characterized by higher (lower) upper roll-off frequencies (the frequencies at which the power begins to decrease) followed by high frequency roll off parts with steep (less steep) slopes. Upper roll-off frequencies in the pre-midnight (post-midnight) are recorded to be in the range $0.9-2.8 \mathrm{~Hz}$ and $0.78-2.3 \mathrm{~Hz}$ (in the range $0.078-0.6 \mathrm{~Hz}$ during post-midnight) at $\mathrm{BOK}$ and RPMC, respectively, while a somewhat lower value in the range $0.7-1.2 \mathrm{~Hz}(\approx 0.06-0.1 \mathrm{~Hz})$ is observed at KNC. Estimation of upper roll-off frequencies help in evaluating the scale sizes of the irregularities through $\sqrt{ } 2 \lambda z$ ( $z$ is the slant range and $\lambda$ is the wavelength, IPP altitude at F-layer is chosen to be $350 \mathrm{~km}$ ). Estimated scale sizes at VHF frequency at

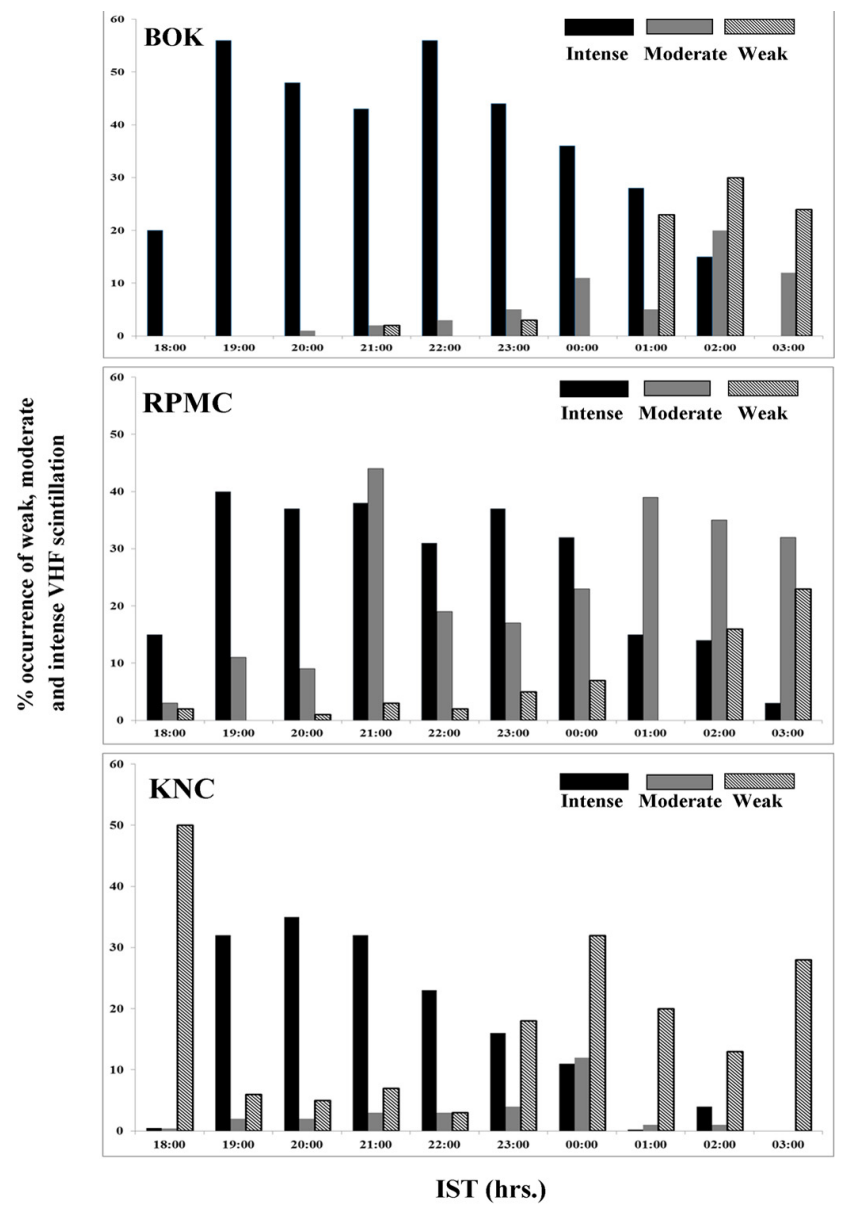

Fig. 6. Bar diagrams showing hourly variation of $S_{4}$ index for weak $\left(S_{4} \approx 0.2-0.4\right)$, moderate $\left(S_{4} \approx 0.4-0.8\right)$ and intense $\left(S_{4}>0.8\right)$ scintillations at BOK, RPMC and KNC during the period of observations.

three stations more or less lie in the range of $990-1000 \mathrm{~m}$. Higher break frequencies at BOK and RPMC than KNC possibly signify an enhancement of forward-scattered power with a larger population of small-scale irregularities (Iyer et al., 2006). Also, higher break frequencies at BOK relative to RPMC and $\mathrm{KNC}$, both during post-sunset and post-midnight period, possibly indicate larger population of small-scale irregularities. The reduced values of break frequencies in the post-midnight period at the three centres in comparison to pre-midnight hours may imply a reduction in the forwardscattered power and larger scale size irregularities mainly contributing to the VHF scintillations (Basu et al., 1980). Temporal variations of spectral indices are shown in Fig. 8a and $\mathrm{b}$ pertaining to post-sunset and post-midnight period respectively. In both the periods, BOK recorded higher spectral indices throughout the patch duration. The high spectral indices in the pre-midnight (post-midnight) hours more or less lie in the range 3.0-7.0 (2.0-4.3) both at RPMC and BOK, while at $\mathrm{KNC}$ a lesser value in the range 2.1-5.5 (1.8-2.5) 
(a) Pre-midnight

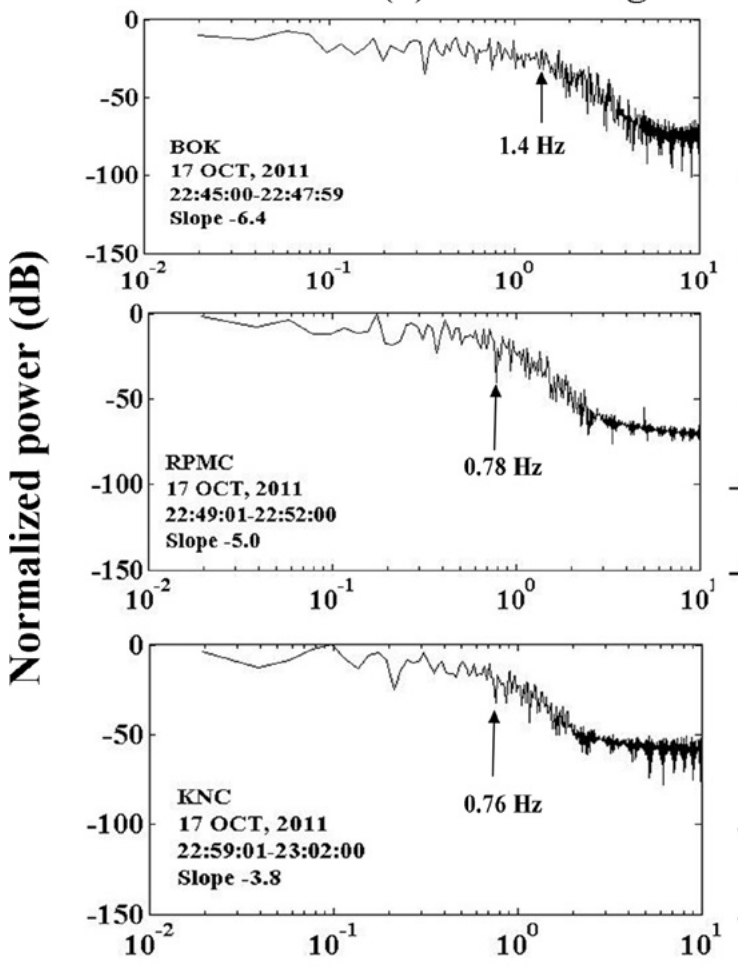

(b) Post-midnight
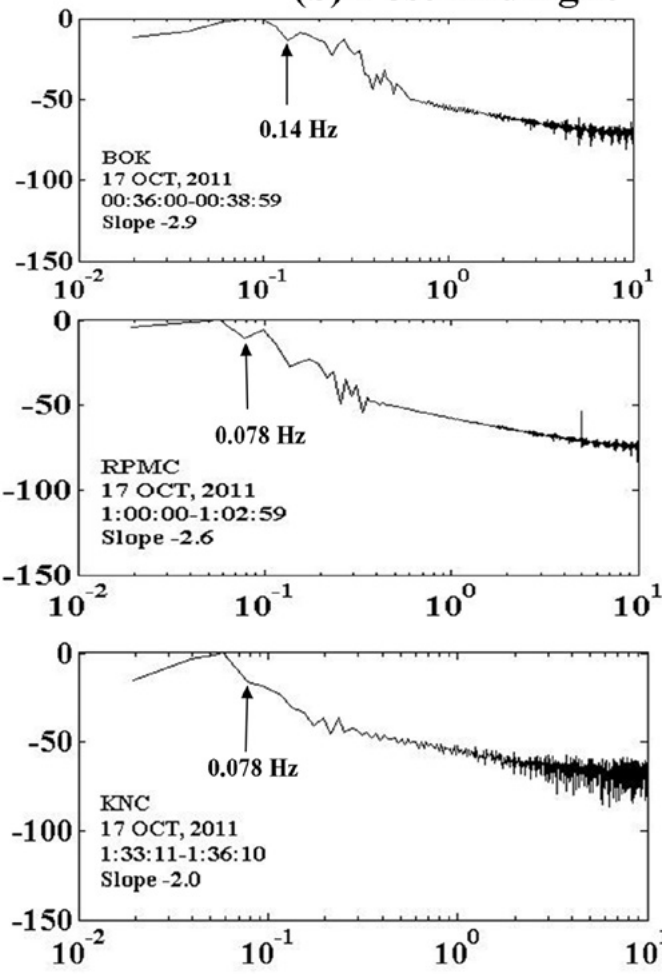

Frequency (Hz)

Fig. 7. Power spectra of (a) pre-midnight and (b) post-midnight amplitude scintillations (250 MHz) as observed from BOK (uppermost panel), RPMC (middle panel) and KNC (lower most panel) on the date and time as mentioned in the diagram. Vertical arrows indicate corresponding break frequencies.

is noted. Steep power spectral slope as high as $\sim 5-6$ for early evening scintillation at $257 \mathrm{MHz}$ frequency near equatorial region of solar maximum period is reported by Basu et al. (1983), and in the range of 2.5-5.6 from equatorial anomaly region by Iyer et al. (2006). The high (low) values of spectral indices in the pre-midnight (post-midnight) hours may be attributed to a thick layer (comparatively thinner) of irregularities, common during equinoctial months of the solar maximum epoch (Rama Rao et al., 2006). In the developing phase, although irregularities of various scale sizes may generate simultaneously, lower scale size irregularities decay first. Both the scale size and the population contribute to the occurrence of scintillation and its strength. Power spectra with steep high-frequency roll-off mainly indicate scattering from multiple structures of different scale sizes (Franke and Liu, 1983). Lower spectral indices at KNC than at BOK and RPMC probably signify a decaying feature of equatorial irregularities.

Figure 4 revealed few cases of moderate VHF scintillations observed at BOK, which sometimes extends to RPMC, barring KNC both during post-sunset (14 and 30 October 2011) and post-midnight hours (21, 23 and 30 October; 6 November 2011). These isolated events consist of scintilla- tion patches with duration $<30$ min with reduced fade rate $<$ $35 /$ min and $<10 /$ min during post-sunset and post-midnight hours respectively. Power spectra analysis (corresponding to $0.8>S_{4}>0.2$ ) mostly showed comparatively lower values of spectral indices at the respective centres with no conspicuous temporal variation of the same throughout the scintillation patch. The spectral analysis corresponding to postsunset and post-midnight scintillation events also reflected Fresnel's oscillation superposed on the high-frequency rolloff part on the majority of cases with the null frequencies obeying Fresnel's square root law (Table 2). On 14 October and 6 November 2011, although Fresnel's oscillation is observed at RPMC, the same is found to be absent at BOK. Presence of Fresnel's oscillations in the power spectra may be indicative of a thin layer of irregularities of thickness $<100 \mathrm{~km}$ (Rama Rao et al., 2005). The available ionosonde data revealed range spread F (RSF) in pre- to post-midnight hours preceding the VHF scintillation in almost every case with the maximum $h^{\prime} F$ lying in the range $\approx 220-227 \mathrm{~km}$ and vertical drift velocity $<20 \mathrm{~m} \mathrm{~s}^{-1}$, which is lower than the maximum $h^{\prime} F>235 \mathrm{~km}$ and vertical drift velocity $>20 \mathrm{~ms}^{-1}$ as observed for simultaneous scintillation observations at three locations during post-midnight 


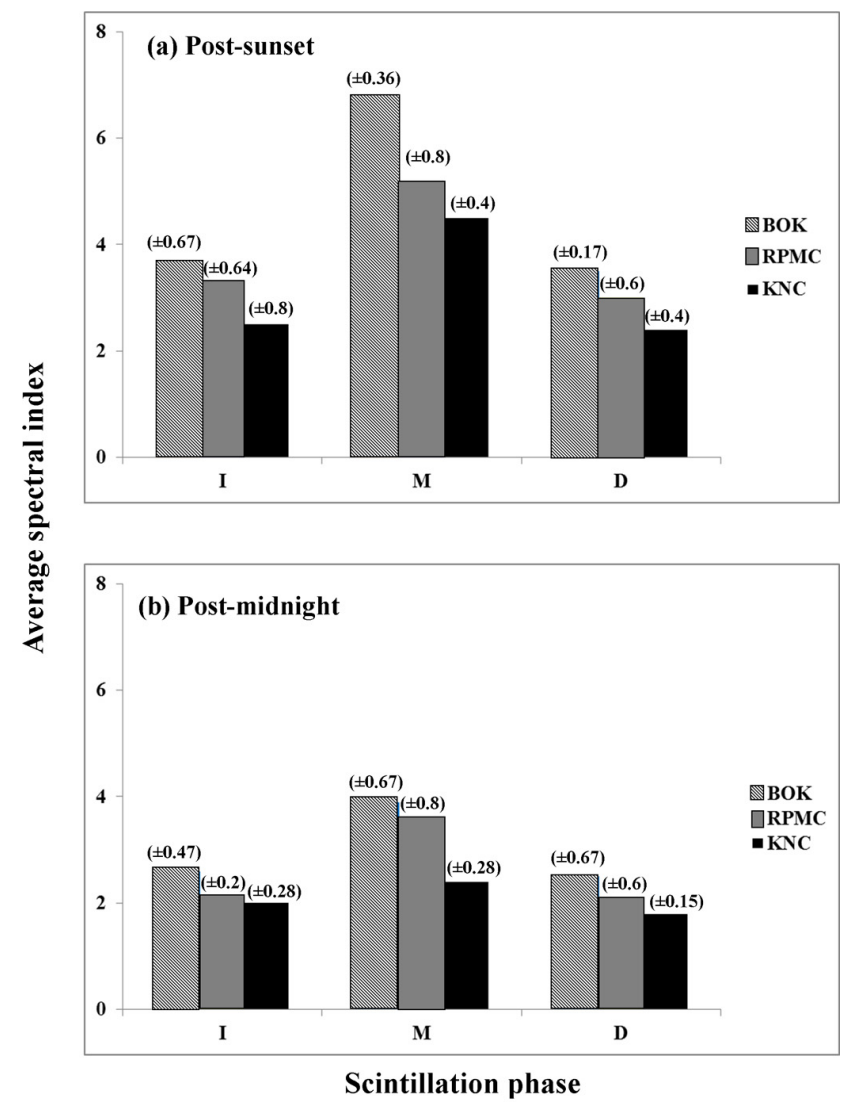

Fig. 8. Variation of average spectral index during the initiation stage $(0-15 \mathrm{~min})$, middle phase $(15-30 \mathrm{~min})$ and decay phase (last $15 \mathrm{~min}$ ) of scintillation patch. The numbers in the brackets indicate standard deviation of the mean. Panel (a) pertains to postsunset while (b) for post-midnight scintillation respectively. "I", "M" and " $\mathrm{D}$ " indicate initial, middle and decay phase respectively. For $S_{4}>0.2$ the initial phase is assumed to start.

hours. Ionosonde data for the days with post-sunset scintillation events are not available to predict such threshold values.

\subsection{Observations at GNSS frequencies}

Along with scintillations at VHF, some of the satellites of the GPS and GLONASS constellation also exhibit severe amplitude scintillations at L1 frequency in excess of $10 \mathrm{~dB}$ in the post-sunset hours for elevation cut-off $>20^{\circ}$. Figure 9 shows a sample plot of I.P.P tracks at $350-\mathrm{km}$ altitude of different GPS and GLONASS satellites on 20 October 2011, showing scintillation (bold portion of track) during the postsunset period as observed from RPMC. It is observed that whenever $S_{4}$ attains a value $>0.6$ and/or $S I_{\mathrm{dB}}>30$, the receiver is badly affected by loss of lock - the state representing equipment malfunction for an average time of $20 \mathrm{~min}$ that sometimes extends even up to $1 \mathrm{~h}$, rigorously hampering TEC observations. Also, it is observed that the sigma phi indices - namely, Phi-01, Phi-30, and Phi-60 - which are defined

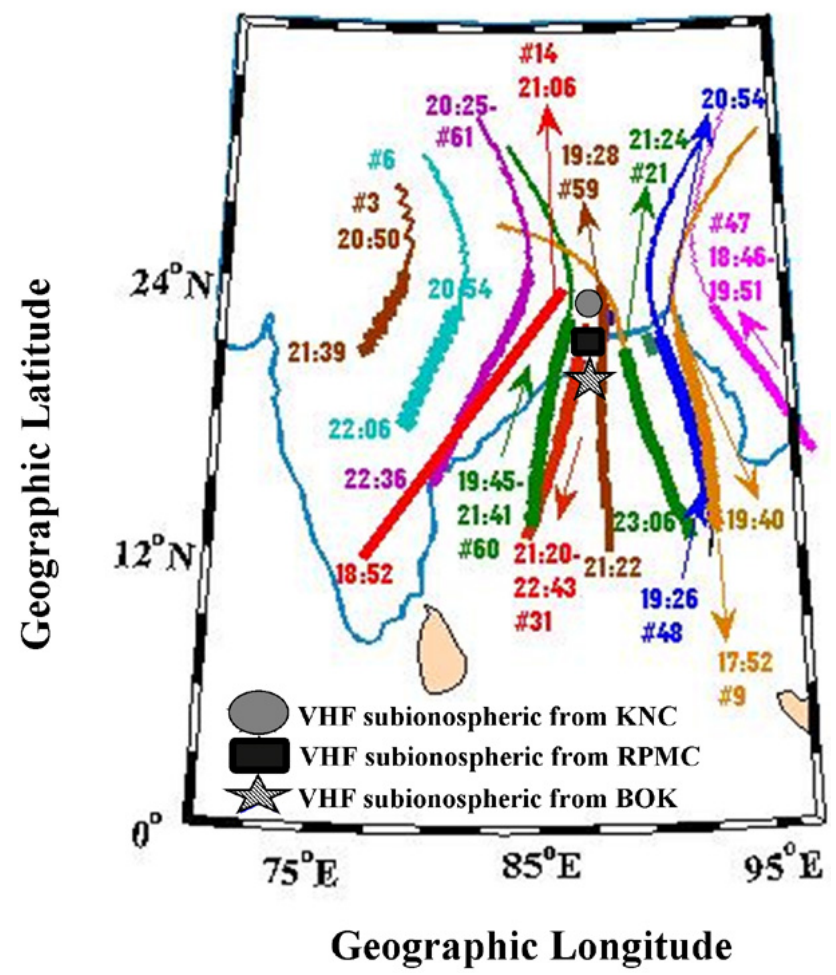

Fig. 9. GPS and GLONASS tracks (geographic) on 20 October 2011 with the bold portions indicating scintillating paths. The initiation and ending time of scintillation are also mentioned. VHF subionospheric locations from three stations are shown by three symbols.

as the standard deviations in radians of the $50-\mathrm{Hz}$ detrended carrier phase averaged over intervals of $1,30,60 \mathrm{~s}$, exhibit NAN value (i.e. non-availability of data). The loss-of-lock condition of the receiver may lead to severe disturbance in the navigation and communication link, resulting in wastage of system resources. The vulnerability of the region exhibiting system disturbances is further demonstrated through the observations at L1 frequencies of various GNSS satellites, which are the major components of the ensuing wide-area augmentation systems (WAAS) like GAGAN in India.

An idea of the latitude extent of irregularity belt may be developed through the observations of scintillations at various GPS/GLONASS satellite tracks. Whenever the satellite tracks extend to latitude $\sim 23-25^{\circ} \mathrm{N}$ no scintillation $\left(S_{4}<0.2\right)$ is observed, whereas frequently recorded moderate to intense scintillations with $S_{4} \sim 0.2-1.2$ are limited up to $\sim 23^{\circ} \mathrm{N}$. Further L-band scintillations are found to be drastically reduced from a high value of $S_{4} \sim 1.0$ to $\sim 0.2$ and even to $<0.1$ for a latitudinal variation of only $0.5-1.0^{\circ}$. Such an extreme variability condition must be taken into account while implementing Indian WAAS. It may be mentioned that the VHF subionospheric point from KNC (VHF) lies around $22.4^{\circ} \mathrm{N}, 86.9^{\circ} \mathrm{E}$ - close to the non-scintillating zone as revealed through GNSS observations. 
Table 2. Spectral features corresponding to some isolated scintillation events at BOK and RPMC (Sect. 3.2).

\begin{tabular}{|c|c|c|c|c|c|c|c|c|c|c|}
\hline \multirow{3}{*}{ Date } & \multicolumn{5}{|c|}{ BOK } & \multicolumn{5}{|c|}{ RPMC } \\
\hline & \multirow{2}{*}{ Spectral index } & \multicolumn{4}{|c|}{ Fresnel's frequency $(\mathrm{Hz})$} & \multirow{2}{*}{ Spectral index } & \multicolumn{4}{|c|}{ Fresnel's frequency $(\mathrm{Hz})$} \\
\hline & & $f_{1}$ & $f_{2}$ & $f_{3}$ & $f_{4}$ & & $f_{1}$ & $f_{2}$ & $f_{3}$ & $f_{4}$ \\
\hline 14 Oct 2011 & 5.7 & \multicolumn{4}{|c|}{ NA } & 4.7 & 0.09 & 0.14 & 0.15 & 0.2 \\
\hline 21 Oct 2011 & 3 & 0.12 & 0.16 & 0.19 & 0.23 & 1.9 & 0.06 & 0.09 & 0.1 & \\
\hline 23 Oct 2011 & 3.7 & 0.11 & 0.16 & 0.19 & 0.23 & No scintillation & \multicolumn{4}{|c|}{ NA } \\
\hline 30 Oct 2011 & 1.2 & 0.09 & 0.14 & 0.17 & 0.21 & No scintillation & & $\mathrm{N}$ & & \\
\hline 6 Nov 2011 & 2.6 & \multicolumn{4}{|c|}{ NA } & 1.6 & 0.29 & 0.39 & 0.49 & 0.6 \\
\hline
\end{tabular}

\subsection{Association with equatorial electrodynamics}

Equatorial scintillation near the anomaly crest is conditioned by the earlier evolution of irregularities, generally called ESF, near the magnetic equator (Somayajulu et al., 1984). Before the commencement of VHF scintillations at the three centres, range type ESF is recorded in post-sunset hours at an equatorial station, Tirunelveli (geographic $8.73^{\circ} \mathrm{N}, 77.7^{\circ} \mathrm{E}$, dip $3.15^{\circ}$ ). It may signify formation of equatorial plasma bubble. The height rise of the bubble containing irregularities and its upper height limit near the magnetic equator dictates the latitudinal extent of the irregularity belt. If the bubble rises to an altitude of about $700 \mathrm{~km}$ over the magnetic equator, its footprint may extend to the crest region. The height rise of the bubble is dictated by the background post-sunset F-layer vertical drift velocity as well as by the drift velocity of the bubble with respect to the background that is mostly controlled by polarization electric field (Anderson and Haerendel, 1979). The signature of background F-layer vertical drift, driven by PRE, may be obtained from $h^{\prime} F$ values near the magnetic equator. It is reported that during post-sunset hours, when the F-layer is above a threshold height of about $300 \mathrm{~km}$, the vertical plasma drift velocity, calculated from ionosonde data obtained from an equatorial station, may correspond to real $\boldsymbol{E} \times \boldsymbol{B}$ drift velocity (Bittencourt and Abdu, 1981). Ionosonde data are available for 28 days, among which post-sunset scintillations are recorded for 19 cases. All the scintillation cases are preceded by range type ESF at the magnetic equator. VHF scintillations at RPMC are observed to follow the height rise of the F-layer before the onset of ESF at Tirunelveli, with maximum $h^{\prime} F$ value in the range $306-462 \mathrm{~km}$. A threshold height ( $h^{\prime} F$ values) required for simultaneous occurrences of scintillations at three centres around EIA crest is estimated to be $370 \mathrm{~km}$ (95\% confidence level). Earlier investigations by Manju et al. (2007) reported a threshold height of $305 \mathrm{~km}$ to cause spread $\mathrm{F}$ near magnetic equator during equinoctial months of the solar maximum year. Vertical plasma drift velocities are estimated from $\mathrm{d} h^{\prime} F / \mathrm{d} t$ at 10 -min time intervals, which are found to lie in the range $19-83 \mathrm{~m} \mathrm{~s}^{-1}$. A threshold value of $31 \mathrm{~m} \mathrm{~s}^{-1}$ may be inferred (at $95 \%$ confidence level) for occurrence of postsunset VHF scintillation near EIA crest preceded by ESF. In the Indian longitude sector, several workers (Chandra et al., 1997; Dabas et al., 2003) have reported a threshold value of $30 \mathrm{~m} \mathrm{~s}^{-1}$ during the high sunspot year for observing scintillations at off-equatorial locations.

The onsets of VHF scintillations, in the post-midnight period at three centres, especially at BOK and RPMC at about 23:30-01:00 IST, are also found to be preceded by ESF at Tirunelveli. However, in this case the vertical plasma drift velocity has been estimated to be quite low, ranging between $\approx 20-24 \mathrm{~m} \mathrm{~s}^{-1}$. The maximum $h^{\prime} F$ values leading to the onset of ESF at Tirunelveli lie in the range $\approx 237-245 \mathrm{~km}$. The lower values of maximum $h^{\prime} F$ and vertical drift velocity compared to the post-sunset period may dictate the limited extent of irregularity belt. The major forces that can drive the ionosphere upward, besides the effect of electric field, are those caused by neutral winds and horizontal advection of plasma (Li et al., 2011). Nicolls et al. (2006) showed that recombination other than zonal electric field may induce apparent midnight uplift at the magnetic equator.

\subsection{Variability of ambient ionization and scintillation}

Amplitude scintillations during equinoctial months are mostly associated with depletion or "bubbles", the signatures of which are reflected in the temporal variations in TEC along the satellite track. The characteristics of depletions, namely amplitude/depth, duration, temporal evolution pattern etc., are analyzed both for RPMC and KNC centres with elevation cut off $\approx 50^{\circ}$. The TEC depletion profiles from both RPMC and KNC resemble identical patterns of temporal variations with differences in amplitude and duration. In general the amplitude or depth of TEC depletion during post-sunset hours lies in the range 7-35 TECU ( 1 TECU $=10^{16} \mathrm{el} \mathrm{m}^{-2}$ ) with durations of 2-30 min as observed from RPMC, while the same is noted to lie in a range of 4-20 TECU from KNC with duration of 2-20 min. The depth of TEC depletion is assumed to be dependent on some factors like local F-region peak density, the magnetic latitude of the observing location (Valladares et al., 2004). If the density is assumed to remain constant along the depleted flux tube (Hanson and Bamgboye, 1984), distinct depletion may be observed near EIA crest. It may be mentioned that 


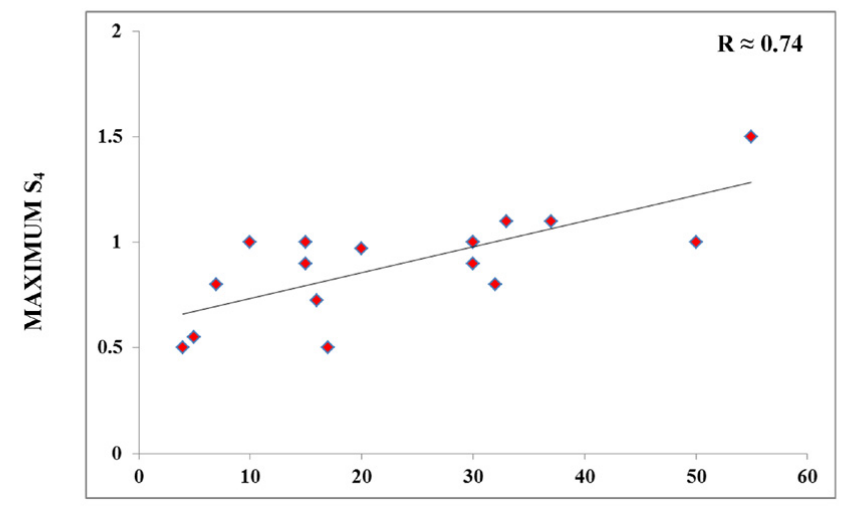

TEC DEPLETION MAGNITUDE (TECU)

Fig. 10. Variations of depletion magnitude in TEC and maximum $S_{4}$ indices as observed on GPS tracks. A highly significant correlation $\approx 0.74$ between the two is reflected.

the strength of scintillation is dependent on amplitude of depletion, which is largely modulated by higher ambient condition. A comparatively higher level of depletions at RPMC than KNC may dictate the variability of scintillation intensity. Huang et al. (1985) from an equatorial anomaly station, Lunping, Taiwan $\left(25^{\circ} \mathrm{N}, 121.17^{\circ} \mathrm{E}\right)$ were unable to detect any statistically significant correlation between maximum TEC depletion and the corresponding scintillation index. A statistical analysis has been made to investigate any probable correspondence between amplitudes of TEC depletion and the maximum $S_{4}$ index at L1 frequency of the corresponding GPS satellites showing TEC depletions as observed from RPMC. Under present investigation a statistically significant (at $5 \%$ significance level) correlation of 0.74 is reflected (Fig. 10).

\section{Discussions}

The results of multistation scintillation observations at VHF $(250 \mathrm{MHz})$ and various L1 frequencies during autumnal equinoctial months (September-November 2011) of the high solar flux period reveal distinguishing traits in the fine structures of scintillation occurrence, such as onset time and duration, fade rates and depth, decorrelation time as well as several spectral features around the three centres (Figs. 3, 4, 5, 6,8 ; Tables 1 and 2). The relative susceptibility of three locations in creating perturbations to transionospheric communication and navigation system over a wide frequency range, extending from VHF to lower microwave band, is also revealed through the analysis. Intense scintillations at VHF as well as L1 frequencies often with peak-to-peak fluctuations of $>30 \mathrm{~dB}$ during the post-sunset period may be attributed to the effects of focussing/refractive scattering (Basu et al., 1996).

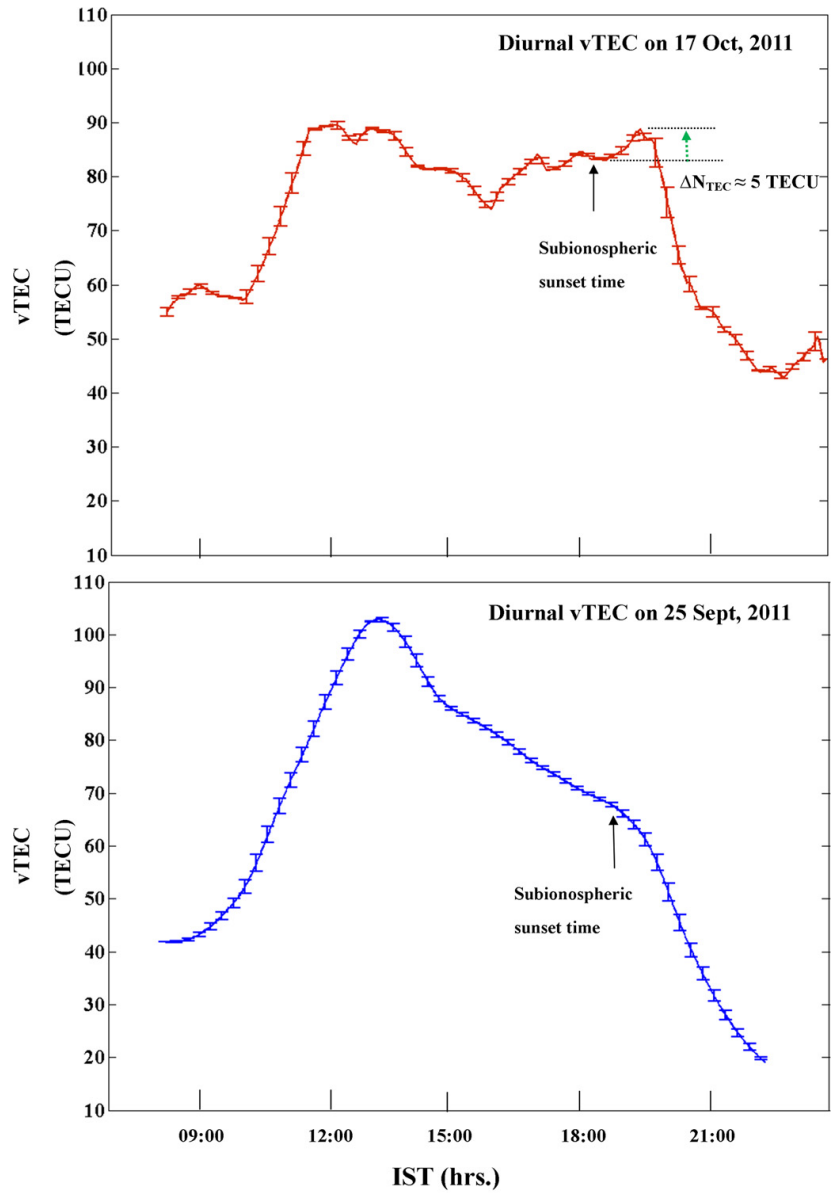

Fig. 11. Diurnal variation of average vTEC (for elevation $>50^{\circ}$ ) on 17 October 2011 (scintillation day) and 25 September 2011 (nonscintillation day) indicating post-sunset enhancement of TEC following subionospheric sunset time (IST) and no enhancement, respectively. Error bars on two plots represent standard deviation of the mean.

Scintillations around the locations are mainly triggered by electron density irregularities generated near the magnetic equator. The evolution and dynamics of equatorial irregularity have been studied by several investigators (Somayajulu et al., 1984; Valladares et al., 2001, 2004) using chain of stations with larger latitudinal span. Observations from largely spatial separated locations may miss fine structures of irregularity features which are evident through the present observations of closely spaced locations.

Intensity of scintillation is determined by the integrated electron density deviation of ionospheric irregularities. Assuming the percentage deviation remains the same, a higher ambient level may correspond to a larger density deviation. The higher solar flux condition results in greater electron density in the F-region leading to enhanced scintillation activity, even at L-band frequencies (Aarons et al., 1981). An idea of high ambient ionization may be obtained from diurnal variation of TEC. Using a simulation study, Klobuchar 


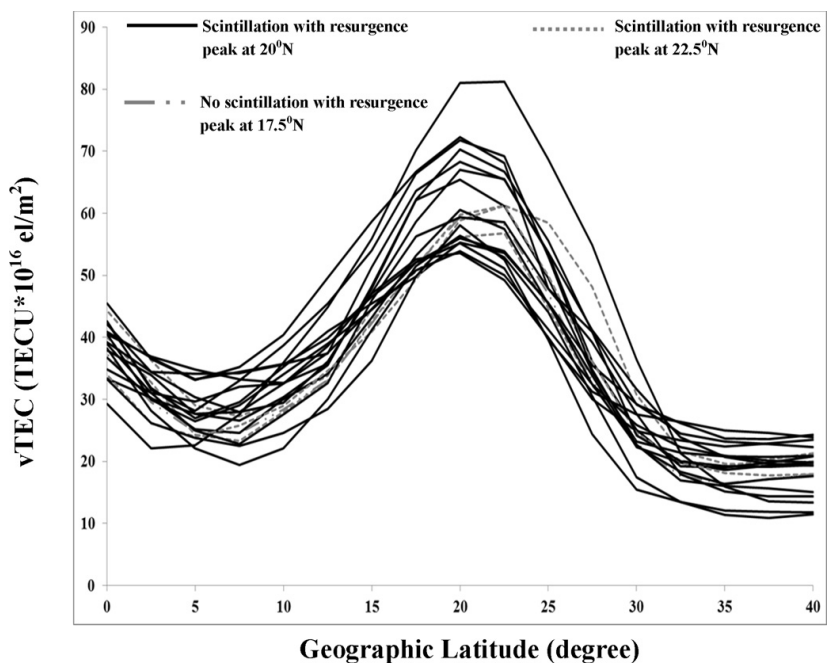

Fig. 12. Mass plot of latitudinal distribution of VTEC, estimated at $85^{\circ} \mathrm{E}$ longitude, around 19:00 IST (=UT $+05: 30 \mathrm{~h}$ ), showing the evening anomaly peaks predominantly situated around $20^{\circ} \mathrm{N}$ (geographic) on most of the days of post-sunset VHF scintillations. For some scintillation days it is around $22.5^{\circ} \mathrm{N}$, while the peak is seen to be around $17.5^{\circ} \mathrm{N}$ for no scintillation cases.

et al. (1991) reported that during high solar flux conditions TEC values at the crests of EIA, which are considered as measure of ambient ionization level, are nearly 5-7 times larger than the corresponding value at the low solar activity period. The diurnal profile of vertical TEC from RPMC indicates secondary enhancement around the sunset period. Earlier studies (Chakraborty et al., 1999) reported a close association between post-sunset enhancement in TEC and scintillations in the equinoctial months of high solar activity years near the anomaly crest. Under present investigation the same approach is extended to study the probable correspondence between TEC enhancement and occurrence of VHF scintillation at three different locations. Diurnal variation of TEC measured through some of the GPS and GLONASS satellites (with an elevation cut off of $50^{\circ}$ ) provides an opportunity to estimate vertical TEC enhancement $\Delta N_{\text {TEC }}$. It has been estimated around local post-sunset hours prior to the commencement of VHF scintillations at RPMC. Figure 11 is a sample plot showing development of secondary enhancement $\Delta N_{\mathrm{TEC}} \approx 5$ TECU on scintillation day (17 October 2011) following subionospheric sunset time (IST) with negligible $\Delta N_{\text {TEC }}$ on non-scintillation day (25 September 2011). Near the anomaly crest, injection of density irregularities in an environment of high ambient ionization triggers intense scintillation activities. An effort has been made to diagnose a threshold value of $\Delta N_{\mathrm{TEC}}$, which may be considered a precursor index for the occurrence of VHF scintillation at BOK, RPMC and KNC. It is observed that whenever $\Delta N_{\text {TEC }}$ values exceed 3 TECU, 5 TECU and 7 TECU, scintillations are registered at $\mathrm{BOK}, \mathrm{RPMC}$ and $\mathrm{KNC}$ with $100 \%$, $93 \%$ and
$75 \%$ probability, respectively (within $95 \%$ prediction limit). The lower occurrence of scintillation at KNC may also be attributed to the zonal drift and decay of irregularities.

The secondary enhancements in TEC are the results of resurgence of EIA driven by pre-reversal enhancement (PRE) of the eastward electric field.. There is strong probability that the equatorial ionization anomaly leaves its signature in the latitude distribution of the height-integrated total electron content (TEC) in the equatorial region (Dasgupta et al., 1985). To develop an idea about the resurgence of anomaly, driven by PRE, latitudinal variations of TEC using IGS data with a time resolution of $15 \mathrm{~min}$ are investigated. A definite signature of resurgence of the post-sunset equatorial anomaly (PEA) in all cases of VHF scintillation is observed. The latitudinal distribution of TEC revealed a post-sunset secondary peak in the majority of the cases to appear $\sim 20^{\circ} \mathrm{N}$, which is close to the VHF subionospheric latitude of BOKKHALI (Fig. 12). Intense VHF scintillation with fast fading rate is often encountered around this location. Severe scintillations are also recorded at RPMC (VHF subionospheric latitude $\sim 21^{\circ} \mathrm{N}$ ) which is located in close proximity to the northern EIA crest whereas KNC (VHF subionospheric latitude $\sim 22^{\circ} \mathrm{N}$ ) witnessed a comparatively less intense and lower occurrence of scintillation. Whenever the evening EIA crest developed around $20-22.5^{\circ} \mathrm{N}$ scintillations are recorded at three locations in majority of cases. The latitudinal distributions of TEC on the days of scintillation inhibition exhibit asymmetry in anomaly structure, sometimes with reduced crest-to-trough ratio. It may be mentioned that the presence of the resurgence peak at $22.5^{\circ} \mathrm{N}$ in post-sunset hours certainly triggers VHF scintillation at KNC, while scintillation may or may not be recorded if the peak is located at about $20^{\circ} \mathrm{N}$. Further, if the resurgence peak is located at latitudes $<20^{\circ} \mathrm{N}$ no scintillation is observed at RPMC as well as at KNC. Under such cases both RPMC and KNC are located in the region beyond the anomaly peak where electron density distribution have negative gradient. It is reported that largest scintillations at latitudes of the EIA tend to be associated with the regions of extremely steep TEC gradients (Basu et al., 2001; Muella et al., 2010). The position of the evening anomaly peak may be a crucial factor in determining the variability of scintillation at three locations. Further, it is also revealed that if the crest-to-trough ratio $(\mathrm{CTR})>2.1$ scintillation is observed at $\mathrm{KNC}$ in $69 \%$ cases. To improve the predictive capability, not only the CTR but also the location EIA peak may be taken into account. Accordingly, a new parameter $(p)$ has been defined by multiplying the crest-to-trough ratio with the evening anomaly peak latitude. It may be noted that if the threshold value for $p$ is taken as $\approx 43$ units, scintillations are recorded at $\mathrm{KNC}$ for $85 \%$ cases. The result is statistically significant at $95 \%$ confidence level. Thus, the locations of the resurgence peak latitude along with CTR, which is a measure of the strength of EIA, may play a significant role for forecasting scintillation at places away from the EIA crest (Jayachandran et al., 1997). 
Indeed, latitudinal extent of the bubble plays the deterministic role in exhibiting scintillations around the anomaly crest. The bubble activity is aggravated by higher ambient level as well as enhanced latitudinal gradient (Basu et al., 2001). Its poleward boundary limits the region of turbulence. The size or growth of bubble seems to be well correlated with the PRE driven EIA strength (Alex et al., 1989; Whalen, 2001; Dabas et al., 2006) and location of EIA crest. Only those bubbles that extent beyond the EIA crests can be detected at $\mathrm{KNC}$, leading to comparatively lesser occurrence of scintillations.

In the post-midnight period, occurrence probability of amplitude scintillations at VHF frequencies is reduced with shorter duration of scintillation, lower values for the $S_{4}$ index, fade rates and spectral index, especially at KNC. Basu et al. (1996) asserted that the magnitude of scintillation is proportional to the height integrated product of the irregularity amplitude $(\Delta N / N)$ and the ionization density along the ray path. The product is largely weighted by the ionization distribution around the peak of the F-layer. In the late evening hours when the F-region descends, both the background density and the irregularity decay due to recombination and diffusive damping resulting in erosion of scintillation features. Also, scintillations at L1 frequency are found to be almost absent during post-midnight period. The scale size of irregularity responsible for scintillation at VHF frequency is $\sim 800-900 \mathrm{~m}$ while smaller scale $(\sim 300-400 \mathrm{~m})$ structures dictate the L-band scintillations. It is reported that in the generation phase of post-sunset hours both the kilometre and metre scale equatorial irregularities co-exist (Basu et al., 1980). In the post-midnight period the small-scale irregularities responsible for L-band scintillations practically cease to exist (Basu et al., 1978; Dasgupta et al., 1985).

The particular isolated scintillation events at BOK and sometimes at RPMC baring KNC on some cases may be associated with a thin layer of weak bottomside spread $\mathrm{F}$ (BSSF) irregularities (Whalen, 1997). It has been reported that post-sunset development of ionospheric irregularity is sometimes associated with the phenomenon of bottomside spread F (BSSF) that are formed below the F-layer maximum (Woodman and La Hoz, 1976; Whalen, 1997, 2000). It is confined to a thin layer in altitude and hence in latitude, disrupting HF/VHF transmission links. BSSF events are often preceded by RSF with the maxima in the pre-midnight period. Equinoctial months pertaining to the solar maxima period may facilitate the BSSF occurrence (Whalen, 2000). It has also been reported that although strong BSSF is a necessary condition for the development of plasma bubbles, weak BSSF may prohibit the bubble formation (Whalen, 2001). The altitudinal and latitudinal limit of weak BSSF irregularities may restrict the occurrence of VHF scintillation to a limited equatorial latitude zone, sometimes up to EIA crest, driven by an increase in altitudinal thickness (Woodman and La Hoz, 1976; Whalen, 2000).

\section{Conclusion}

An extensive investigation on the multistation occurrences of ionospheric scintillations from the three locations with smaller latitudinal separation around the northern crest of equatorial anomaly and beyond reveals extreme variability, both in spatial and temporal domain, in the occurrence pattern. While the regions near the EIA crest and its equatorward edge are much susceptible to irregularity activities, less vigorous ionospheric state seems to prevail just beyond the crest. Intense scintillations with fast fading rate plague the region over the anomaly crest; comparatively lesser fade depth and fade rate characterize the region beyond the same. The post-sunset period of equinoctial months of the high solar activity year is most vulnerable to exhibiting frequent severe scintillation activities dictated by co-existence of both smaller to larger scale size irregularities in an environment of high ambient ionization. A somewhat lesser ambient condition and dominance of larger scale size irregularities in the post-midnight period reduce severity of scintillations at VHF frequency. Locations of the observing stations with respect to the resurgence EIA peak driven by PRE seem to play a deterministic role in dictating scintillation activity. Not only the crest-to-trough ratio (CTR), which is a signature of EIA strength, but also the product of CTR and spatial location of crest may be considered as a precursor index for simultaneous occurrence of scintillations at three locations. The latitudinal extensions of the bubble limit the scintillation activity around the anomaly crest. The bubble activity is accentuated by the enhanced gradient and strength of EIA. The threshold amplitude of secondary enhancement in diurnal vTEC is also found to be an important index for predicting occurrence and non-occurrence of scintillation and its spatial variability. A threshold value of $h^{\prime} F$ near the magnetic equator for simultaneous occurrence of scintillation at the three centres is also suggested. Results of multistation observations from the extremely vulnerable region thus accrued may form an important database to be utilized by the system engineers to decide the grid size of the Indian WAAS program (GAGAN) as well as fade margin of the receiving system for fail-safe designing of communication links. The extent of ionospheric variability as revealed through studies of scintillation and TEC near the equatorial anomaly crest may form an important database for modelling of ionospheric scintillation, which is a major concern of present-day space research activities.

Acknowledgements. The authors are greatly indebted to A. DasGupta, C.U. for valuable suggestions and fruitful discussions. The work has been carried out with the financial assistance of Department of Science and Technology, Government of India under SERC project. The authors thank D. Tiwari, Indian Institute of Geomagnetism, India for supplying ionosonde data.

Topical Editor K. Hosokawa thanks L. Alfonsi and one anonymous referee for their help in evaluating this paper. 


\section{References}

Aarons, J., Whitney, H. E., MacKenzie E., and Basu, S.: Microwave equatorial scintillation intensity during solar maximum, Radio Sci., 16, 939-945, 1981.

Abdu, M. A., de Medeiros, R. T., Sobral, J. H. A., and Bittencourt, J. A.: Spread F plasma bubble vertical rise velocities determined from spaced ionosonde observations, J. Geophys. Res., 88, 9197-9204, 1983.

Alex, S., Koparkar, P. V., and Rastogi, R. G.: Association between equatorial and tropical spread-F, J. Atmos. Terr. Phys., 51, 371379, 1989.

Anderson, D. N.: A semi-empirical low-latitude ionospheric model, Radio Sci., 22, 292-306, 1987.

Anderson, D. N. and Haerendel, G.: The Motion of Depleted Plasma regions in the Equatorial Ionosphere, J. Geophys. Res., 84, 42514156, 1979.

Basu, S. and Basu, Su.: Equatorial scintillations - a review, J. Atmos. Terr. Phys., 43, 473-489, 1981.

Basu S., Basu, Su, Aarons, J., McClure, J. P., and Cousins, M. D.: On the coexistence of kilometre- and meter-scale irregularities in the night time equatorial F region, J. Geophys. Res., 83, 42194226, 1978.

Basu, S., McClure, J. P., Basu, Su, Hanson, W. B., and Aarons, J.: Coordinated Study of Equatorial Scintillation and In Situ and Radar Observations of Nighttime F region Irregularities, J. Geophys. Res., 85, 5119-5130, 1980.

Basu, Su., Basu, S., McClure, J. P., and Hanson, W. B., and Whitney, H. E.: High resolution Topside In Situ Data of Electron Densities and $\mathrm{VHF} / \mathrm{GHz}$ scintillations in the equatorial Region, J. Geophys. Res., 88, 403-415, 1983.

Basu, S., MacKenzie, E., and Basu, Su.: Ionospheric constraints on VHF/UHF communication links during solar maximum and minimum periods, Radio Sci., 23, 363-378, 1988.

Basu, S., Kudeki, E., Basu, Su., Valladares, C. E., Weber, E. J., Zengingonul, H. P., Bhattacharyya, A., Sheehan, R., Meriwether, J. W., Boindi, M. A., Kuenzler, H., and Espinoza, J.: Scintillations, plasma drifts, and neutral winds in the equatorial ionosphere, J. Geophys. Res., 101, 26783-26795, 1996.

Basu, Su., Basu, S., Valladares, C. E., Yeh, H. C., Su, S. Y., Mackenzie, E., Sultan, P. J., Aarons, J., Rich, F. J., Dohery, P., Groves, K. M., and Bullett, T. W.: Ionospheric effects of major magnetic storms during the International Space Weather Period of September and October 1999: GPS observations, VHF/UHF scintillations, and in situ density structures at middle and equatorial latitudes, J. Geophys. Res., 106, 30389-30413, 2001.

Basu, S., Groves, K. M., Basu, S., and Sultan, P. J.: Specification and forecasting of scintillations in communication/navigation links: current status and future plans, J. Atmos. Solar-Terr. Phys., 64, 1745-1754, 2002.

Bhar, J. N., Das Gupta, A., and Basu, S..: Studies on F- region irregularities at low latitude from scintillations of satellite signals, Radio Sci., 5, 939-942, 1970.

Bhattacharya, A. and Rastogi, R. G.: Amplitude scintillations during the early and late phases of evolution of irregularities in the nighttime equatorial ionosphere, Radio Sci., 20, 935-946, 1985.

Bittencourt, J. A. and Abdu, M. A.: A theoretical comparison between apparent and real vertical ionization drift velocities in the equatorial F region, J. Geophys. Res., 86, 2451-2454, 1981.
Burke, W. J., Huang, C. Y., Valladares, C. E., Machuzak, J. S., Gentile, L. C., and Sultan, P. J.: Multipoint observations of equatorial plasma bubbles, J. Geophys. Res., 108, 1221, doi:10.1029/2002JA009382, 2003.

Carrano, C. S., Valladares, C. E., and Groves, K. M.: Latitudinal and Local Time Variation of Ionospheric Turbulence Parameters during the conjugate Point Equatorial Experience in Brazil, Int. J. Geophys., 2012, 1-16, doi:10.1155/2012/103963, 2012.

Chakraborty, S. K., Dasgupta, A., Ray, S., and Banerjee, S.: Longterm observations of VHF scintillations and total electron content near the crest of the equatorial anomaly in the Indian longitude zone, Radio Sci., 34, 241-255, 1999.

Chandra, H., Vyas, G. D., Sinha, H. S. S., Prakash, S., and Misra, R. N.: Equatorial spread-F campaign over SHAR, J. Atmos. Terr. Phys., 59, 191-205, 1997.

Dabas, R. S. and Reddy, B. M.: Nighttime VHF scintillations at $23^{\circ} \mathrm{N}$ magnetic latitudes and their association with equatorial $\mathrm{F}$ region irregularities, Radio Sci., 21, 453-462, 1986.

Dabas, R. S. and Reddy, B. M.: Equatorial plasma bubble rise velocities in the Indian sector determined from multistation scintillation observations, Radio Sci., 25, 125-132, 1990.

Dabas, R. S., Singh, L., Lakshmi, D. R., Subramanyam, P., Chopra, P., and Garg, S. C.: Evolution and dynamics of equatorial plasma bubbles: Relationships to $\boldsymbol{E} \times \boldsymbol{B}$ drift, postsunset total electron content enhancements, and equatorial electrojet strength, Radio Sci., 38, 1075-1086, doi:10.1029/2001RS002586, 2003.

Dabas, R. S., Singh, L., Garg, S. C., Das, R. M., Sharma, K., and Vohra, V. K.: Growth and decay of a post-sunset equatorial anomaly at low latitudes: Control of E X B, neutral winds and daytime electrojet strength, J. Atmos. Terr. Phys., 68, 16221632, 2006.

Dasgupta, A., Anderson, D. N., and Klobuchar, J. A.: Modeling the low latitude ionospheric total electron content, J. Atmos. Sol. Terr. Phys., 47, 917-925, 1985.

de Paula, E. R., Rodrigues, F. S., Iyer, K. N., Kantor, I. J., Kintner, P. M., Ledvina, B. M., and Kil, H.: Equatorial Anomaly Effects on GPS scintillations in Brazil, Adv. Space Res., 31, 749-754, 2003.

Franke, S. J. and Liu, C. H.: Observations and modeling of multifrequency VHF and $\mathrm{GHz}$ scintillations in the equatorial region, J. Geophys. Res., 88, 7075-7085, 1983.

Hanson, W. B. and Bamgboye, D. K.: The measured motions inside equatorial plasma bubbles, J. Geophys. Res., 89, 8997-9008, 1984.

Huang, Y. N.: Ionospheric Electron Content Depletion Associated with Amplitude Scintillation at the Equatorial Anomaly Crest Region, J. Geophys. Res., 90, 4333-4339, 1985.

Iyer, K. N., Jivani, M. N., Abdu, M. A., Joshi, H. P., and Aggarwal, M.: Power spectral studies of VHF ionospheric scintillations near the crest of the equatorial anomaly in India, Indian J. Radio and Space Physics, 35, 234-241, 2006.

Jayachandran, P. T., Sri Ram, P., Somayajulu, V. V., and Rama Rao, P. V. S.: Effect of equatorial ionization anomaly on the occurrence of spread-F, Ann. Geophys., 15, 255-262, doi:10.1007/s00585-997-0255-3, 1997.

Kelley, M. C., Makela, J. J., Paxton, L. J., Kamalabadi, F., Comberiate, J. M., and Kil, H.: The first coordinated ground-based and space-based optical observations of equatorial plasma bubbles, Geophys. Res. Lett., 30, 1766, doi:10.1029/2003GL017301, 
2003.

Kil, H., Kinter, P. M., de Paula, E. R., and Kantor, I. J.: Latitudinal variations of scintillation activity and zonal plasma drifts in South America, Radio Sci., 37, 1006, doi:10.1029/2001RS002468, 2002.

Kinter, P. M., Kil, H., Beach, T. L., and de Paula, E. R.: Fading timescales associated with GPS signals and potential consequences, Radio Sci., 36, 731-743, 2001.

Klobuchar, J. A., Anderson, D. N., and Dohery, P. H.: Model studies of the latitudinal extent of the equatorial anomaly during equinoctial conditions, Radio Sci., 26, 1025-1047, 1991.

Knepp, D. L.: Effects of ionospheric scintillation on Transit satellite measurement of total electron content, Radio Sci., 39, RS1S11, doi:10.1029/2002RS002825, 2004.

Li, G., Ning, B., Abdu, M. A., Yue, X., Liu, L., Wan, W., and Hu, L.: On the occurrence of postmidnight equatorial $F$ region irregularities during the June solstice, J. Geophys. Res., 116, A04318, doi:10.1029/2010JA016056, 2011.

Manju, G., Devasia, C. V., and Sridharan, R.: On the seasonal variations of the threshold height for the occurrence of equatorial spread F during solar minimum and maximum years, Ann. Geophys., 25, 855-861, doi:10.5194/angeo-25-855-2007, 2007.

Muella, M. T. A. H., Kherani, E. A., de Paula, E. R., Cerruti, A. P., Kinter, P. M., Kantor, I. J., Mitchell, C. N., Batista, I. S., and Abdu, M. A.: Scintillation-producing Fresnel-scale irregularities associate with the regions of steepest TEC gradients adjacent to the equatorial ionization anomaly, J. Geophys. Res., 115, A03301, doi:10.1029/2009JA014788, 2010.

Nicolls, M. J., Kelley, M. C., Vlasov, M. N., Sahai, Y., Chau, J. L., Hysell, D. L., Fagundes, P. R., Becker-Guedes, F., and Lima, W. L. C.: Observations and modeling of post-midnight uplifts near the magnetic equator, Ann. Geophys., 24, 1317-1331, doi:10.5194/angeo-24-1317-2006, 2006.

Ossakow, S. L.: Spread-F theories - A review, J. Atmos. Terr. Phys., 43, 437-452, doi:10.1016/0021-9169(81)90107-0, 1981.

Paul, A., Chakraborty, S. K., Das, A., and Das Gupta, A.: Estimation of satellite-based augmentation system grid size at low latitudes in the Indian zone, J. Inst. Nav., 52, 15-22, 2005.

Rama Rao, P. V. S., Tulasi Ram, S., Niranjan, K., Prasad, D. S. V. V. D, Gopi Krishna, S., and Lakshmi, N. K. M.: VHF and Lband scintillation characteristics over an Indian low latitude station, Waltair $\left(17.7^{\circ} \mathrm{N}, 83.3^{\circ} \mathrm{E}\right)$, Ann. Geophys., 23, 2457-2464, doi:10.5194/angeo-23-2457-2005, 2005.
Rama Rao, P. V. S., Tulsi Ram, S., Gopi Krishna, S., Niranjan, K., and Prasad, D. S. V. V. D.: Morphological and spectral characteristics of L-band and VHF scintillations and their impact on transionospheric communications, Earth Planets Space, 58, 895-904, 2006.

Rino, C. and Owen, J.: The time structure of transionospheric radio wave scintillation, Radio Sci., 15, 479-489, 1980.

Somayajulu, Y. V., Garg, S. C., Dabas, R. S., Lakha Singh, Tyagi, T. R., Lokanadham, B., Ramakrishna, S., and Navneeth, G.: Multistation study of nighttime scintillations in low latitudes: Evidence of control by equatorial $\mathrm{F}$ region irregularities, Radio Sci., 19, 707-718, 1984.

Valladares, C. E., Basu, S., Groves, K., Hagan, M. P., Hysell, D., Mazzella Jr., A. J., and Sheehan, R. E.: Measurement of the latitudinal distributions of total electron content during equatorial spread-F events, J. Geophys. Res., 106, 29133-29152, 2001.

Valladares, C. E., Villalobos, J., Sheehan, R., and Hagan, M. P.: Latitudinal extension of low-latitude scintillations measured with a network of GPS receivers, Ann. Geophys., 22, 3155-3175, doi:10.5194/angeo-22-3155-2004, 2004.

Whalen, J. A.: Equatorial bubbles observed at the north and south anomaly crests: Dependence on season, local time and dip latitude, Radio Sci., 32, 4, 1559-1566, 1997.

Whalen, J. A.: An equatorial bubble: Its evolution observed in relation to bottomside spread $\mathrm{F}$ and to the Appleton anomaly, J. Geophys. Res., 105, 5303-5315, 2000.

Whalen, J. A.: The equatorial anomaly: Its quantitative relation to equatorial bubbles, bottomside spread $\mathrm{F}$ and $\boldsymbol{E} \times \boldsymbol{B}$ drift velocity during a month at solar maximum, J. Geophys. Res., 106, 2912529132, 2001.

Whalen, J. A.: The linear dependence of GHz scintillation on electron density observed in the equatorial anomaly, Ann. Geophys. 27, 1755-1761, doi:10.5194/angeo-27-1755-2009, 2009.

Whitney, H. E. and Basu, S.: The effect of ionospheric scintillation on VHF/UHF satellite communications, Radio Sci., 12, 123-133, 1977.

Woodman, R. F. and La Hoz, C.: Radar observations of F region equatorial irregularities, J. Geophys. Res., 81, 5447-5466, 1976.

Yeh, K. C. and Liu, C. H.: Radio Wave Scintillations in the Ionosphere. Proceedings of the IEEE, 70, 324-360, 1982. 